\title{
Um equipamento demonstrativo de levitação magnéti- ca de uma bobina com automatização adaptada aos Museus de Ciência e Tecnologia ${ }^{+*}$
}

Osmar Henrique Moura da Silva

Carlos Eduardo Laburú

Sérgio de Mello Arruda

Irinéa de Lourdes Batista

Departamento de Física - UEL

Londrina - PR

\section{Resumo}

Este trabalho insere-se numa linha de publicações deste periódico em que as contribuições estão baseadas no desenvolvimento de equipamentos destinados aos ambientes de educação informal como os Museus de Ciência e Tecnologia (MCTs) e similares. Apresenta-se aqui uma proposta de elaboração de um equipamento de levitação magnética de uma bobina com automatização inovadora para que os próprios visitantes realizem a demonstração de forma simples, com segurança e dentro da perspectiva de entretenimento que esses lugares anseiam.

Palavras-chave: Experimento. Levitação magnética de uma bobina. Educação informal. Museu de Ciência e Tecnologia.

\footnotetext{
An equipment to demonstrate magnetic levitation of a coil with adapted automation to suit Science and Technology Museums

* Recebido: agosto de 2013.

Aceito: novembro de 2013.
} 


\begin{abstract}
This work is part of a line publications of this journal whose contributions describe the development of an equipment to informal education settings such as Science and Technology Museums (STM) and similar. We present a proposal to develop a device for magnetic levitation coil with innovative automation so that the visitors themselves perform the demonstration in a simple and safe way within the perspective of entertainment that these places aim.
\end{abstract}

Keywords: Experiment. Magnetic levitation coil. Informal education. Science and Technology Museum.

\title{
I. Introdução
}

Fascinante fenômeno em que um objeto se encontra suspenso no ar sem qualquer contato físico ou apoio aparente, a levitação pode ser alcançada pelas reconhecidas técnicas: mecânica, por uso de forças pneumáticas ('hovercraft') ou aerodinâmicas (avião); elétrica, em que há forças eletrostáticas (JEON; HIGUCHI, 1998) ${ }^{1}$; e magnética. Esta última, definida como levitação magnética, é percebida mediante o uso de forças magnéticas contrárias às forças da gravidade. Na literatura especializada, embora diferenciadas classificações sistemáticas de técnicas de levitação magnética possam ser discutidas (BLEULER, 1992; JAYMANT, 1981), essencialmente vale destacar: a da levitação eletromagnética (EML) ${ }^{2}$, caso típico de um eletroímã controlando por atração e abaixo dele a posição no ar de um elemento ferromagnético; a da levitação supercondutora (SQL), baseada na propriedade diamagnética dos supercondutores para expulsão de campos magnéticos estáticos do seu interior, um fenômeno conhecido como efeito Meissner; e a da levitação eletrodinâmica (EDL), que emprega um condutor não ferromagnético na presença de um fluxo magnético variável e indutor de correntes de Foucault neste condutor (lei de Faraday-Lenz), cuja força magnética resultante das interações entre correntes e campos magnéticos é repulsiva (LANG; AXT, 2003). Em termos

\footnotetext{
${ }^{1}$ Para ver um simples experimento: https://www.youtube.com/watch?v=DRBAPd7N0IE.

2 Ainda é possível deparar-se com a palavra suspensão no lugar de levitação nas siglas mencionadas e respeitadas em inglês: EML (Electromagnetic Levitation); SQL (Superconducting Quantum Levitation); EDL (Electrodynamics Levitation).
} 
aplicativos, as três técnicas de levitação magnética destacam-se devido à intensidade da força que produzem sendo utilizadas nos sistemas de transporte de alta velocidade popularmente conhecidos como trens "Maglev" (COSTA, 2005), com demais esclarecimentos nesse sentido e outros interesses de investigação tecnológica em Lee et al. (2006).

Educacionalmente, há uma variedade de experimentos demonstrativos de levitação magnética que podem servir de subsídio às discussões sobre o tema. Os comercializados estão fortemente caracterizados com a levitação eletromagnética em duas subclasses: tipo ativa exemplificada no "Globo flutuante' (eletroímã e material ferromagnético ${ }^{4}$ ) e tipo passiva no "Levitron" (ímãs permanentes mantidos afastados com um deles suspenso no ar), podendo este ser montado com materiais alternativos em que vídeos na internet disponibilizam tal orientação ${ }^{6}$. Para o caso da levitação supercondutora ${ }^{7}$, é trivial realizá-la tendo-se um supercondutor, um ímã permanente e um pequeno reservatório de isopor com nitrogênio líquido (ROCHA \& FRANQUELLI, 2004) ${ }^{8}$. Já a levitação eletrodinâmica é basicamente obtida ou com ímã permanente próximo à superfície de um condutor não ferromagnético, estando eles em movimentos relativos entre si ${ }^{9}$, ou com bobina de circulação de corrente alternada $(\mathrm{CA})$ próxima à superfície, preferencialmente plana e de área equivalente ou superior à da bobina, de um condutor não ferromagnético espesso ${ }^{10}$. O versado experimento Anel de Thompson (LANG; AXT, 2003) consti-

\footnotetext{
${ }^{3}$ Ou Globo Magnético de Levitação <http://www.youtube.com/watch?v=QBPvHoM8lnc>.

${ }^{4}$ Valle et al. (2012) apresentam um curioso experimento didático de levitação de um disco de material ferromagnético por meio de eletroímã, cuja demonstração pode ser vista em: $<$ http://www.youtube.com/watch?v=BWYCe1PBoW8>.

Originalmente um brinquedo em que se fazem ajustes da inclinação da base e de um conjunto de pequenos pesos acrescentados ao pião para que este gire flutuando sobre a base $<$ http://www.youtube.com/watch? $\mathrm{v}=\mathrm{GMVtlNbMwHw}>$.

${ }^{6}<$ http://www.youtube.com/watch?v=pNJ2EmR6GNo $>$

${ }^{7}<$ http://www.youtube.com/watch?v=Mz4YWU6ds5g >

Estes autores utilizam o supercondutor $\mathrm{YBa}_{2} \mathrm{Cu}_{3} \mathrm{O}_{7}$ e detalham uma técnica para sua confecção com instrumentos específicos.

${ }^{9}<$ http://www.youtube.com/watch?v=rkxUL-_lqyI $>$

${ }^{10}<$ http://www.youtube.com/watch?v=PXmrJvEi7Fs\&NR=1\&feature=endscreen $>$
} 
tui um dos mais simples tipos de levitação eletrodinâmica e, de maior complexidade, outro exemplo está na levitação controlada de chapas metálicas sobre bobinas (BELKELMAN; DZADOVXKY, 2008).

Entretanto, todas essas demonstrações citadas exigem preparações de arranjos experimentais por aqueles previamente empenhados em realizá-las (educadores, estudantes ou estagiários) e não se adequam às situações dos Museus de Ciência e Tecnologia (MCTs) e similares, nos quais os mais variados visitantes são designados eles próprios a livremente experimentarem o que lá se encontra preparado dentro de uma perspectiva de entretenimento (SILVA et al., 2013a; CHELINI; LOPES, 2008, p. 228 e 235; VALENÇA, 2006, p. 333; CAZELLI apud CONSTANTIN, 2001, p. 197). Para Pavão e Leitão (2007, p. 41), além do entretenimento e informação, os experimentos interativos "representam um progresso ao oferecerem certo envolvimento lúdico do público", entendimento este exemplificado por Bonatto et al. (2007, p. 49). Diferenciando-se do ensino escolástico tradicional, nesses ambientes de educação informal buscam-se uma maneira divertida (PAVÃO; LEITÃO, 2007, p. 44) de envolver o conhecimento científico em que os equipamentos necessitam de adaptações. Além de explicações dos fenômenos pensadas com linguagem acessível à maioria dos experimentadores, textos que induzem o que observar e comandos de acionamento são indispensáveis. Conforme Iszlaji (2012, p. 90), nos MCTs grande parte das interações com os aparatos tem o interesse despertado por um "simples 'girar manivelas' ou aperto de um botão tipo push-button (apertar um botão para obter uma única resposta)", em que muitos equipamentos são constituídos de uma automatização arquitetada por uma equipe especializada do setor.

$\mathrm{Na}$ intenção de contribuir para aqueles comprometidos com a educação científica informal, o presente trabalho divulga a elaboração de um equipamento que é acionado por um único botão e realiza a levitação magnética de uma bobina, controlada eletronicamente. A automatização na montagem é inovadora e apoia-se nas indispensáveis preocupações: individualmente, qualquer experimentador deve alcançar êxito na demonstração; o equipamento necessita de proteção contra danos previsivelmente ocasionados por 'curiosidades' indesejadas em razão de ele poder ser livremente acessado pelos visitantes no dia-a-dia ${ }^{12}$; os visitantes devem estar

\footnotetext{
${ }^{11}$ Inserido numa linha de publicações (SILVA et al. 2013a; SILVA et al., 2013b; SILVA, ZAPAROLLI; ARRUDA, 2012; SILVA; LABURÚ, 2009) com contribuições que descrevem desenvolvimentos de experimentos destinados a MCTs.

${ }^{12}$ Quando desligada, por exemplo, alguém poderia 'remexer' a bobina e estragá-la.
} 
seguros ao manipularem o equipamento, impossibilitando acidentes causados por choques elétricos ou queimaduras num contato físico com a bobina superaquecida perante inoportuna falha elétrica ou eletrônica.

\section{Metodologia de construção e materiais utilizados}

Esta seção encarrega-se da elaboração do equipamento de levitação magnética mencionado. Devido à diversidade de itens empregados e das particularidades procedimentais, busca-se melhor orientar esta construção por meio de três subseções assim denominadas: A bobina e o sistema de refrigeração; $\mathrm{O}$ circuito de controle automático; A montagem final. Como integrante desta última seção, um anexo é apresentado. Nele se expõe um modelo aqui pensado relativo ao comando de orientação com sintética explicação do fenômeno em linguagem inteligível ao público alvo, elaborada a partir de uma discussão qualitativa que se faz do princípio físico da levitação magnética observada.

\section{II.1 A bobina e o sistema de refrigeração}

A bobina, tipo solenoide compacto, é feita de fio de cobre esmaltado n. 18 AWG (1,02 mm de diâmetro) nas dimensões: $18 \mathrm{~cm}$ de diâmetro externo; $11 \mathrm{~cm}$ de diâmetro interno; e $4 \mathrm{~cm}$ de altura. Isto totaliza cerca de 800 espiras, sendo possível usar fita adesiva dupla face (transparente) para ajudar a unir as camadas de espiras durante a confecção. No fim, quatro (ou mais) amarrações transversais com finos fios de nylon (típicos usados para pesca) firmam a bobina e protegem sua estrutura dos impactos de queda após os repentinos desligamentos. Assim aprontada, a bobina está 'adaptada a ${ }^{13}$ à tensão padronizada de $220 \mathrm{~V}$. A escolha desta tensão ocorre em razão de se recomendar a aparência de uma grande e pesada bobina na intenção de aumentar tanto o efeito visual pela levitação de um objeto maior como o efeito sonoro pela batida na queda do mesmo, acreditando-se que dessa forma mais bem beneficiado seja o estímulo da atenção de um curioso na demonstração (WAGENSBERG, 2003) ${ }^{14}$. A Fig. 1 mostra essa bobina, cujos terminais são conectados no circuito eletrônico tratado mais adiante. Aliás, caso haja o interesse em usar a tensão padrão de $127 \mathrm{~V}$, pode-se reduzir os valores indicados

\footnotetext{
${ }^{13}$ Adaptação conforme automatização.

14

${ }^{14}$ Para Girault e Guichard (apud CHELINI; LOPES, 2008, p. 233), a exposição pode "criar um impacto emocional que estimula o interesse do visitante e favorece a memorização".
} 
para a elaboração da bobina em torno de $60 \%$ e seguir uma pequena modificação no circuito eletrônico comentado na Fig. 2.

Uma caixa quadrada de acrílico (chapa $5 \mathrm{~mm}$ ) para envolver a bobina é amoldada com $31 \mathrm{~cm}$ de lado e $8 \mathrm{~cm}$ de altura, porém, com duas opostas laterais abertas. Considerando desejada a vista frontal transparente para observação interna da bobina e de sua levitação ${ }^{15}$, adaptam-se nessas aberturas laterais da caixa oito ventoinhas do tipo usadas em fontes de computadores de modo a internamente produzirem refrigerantes fluxos de ar. Conforme se vê na Fig. 1, de um lado, quatro delas são alinhadas para soprar o ar de fora para dentro e, inversamente, do outro lado, quatro são posicionadas para soprar o ar de dentro para fora. Todas as ventoinhas são ligadas em paralelo e conectadas no circuito eletrônico, seguindo as orientações nesse sentido pelo esquema elétrico da próxima subseção. Para terminar essa montagem da caixa, aconselham-se acrescentar externamente junto às ventoinhas telas protetoras de arame, visíveis na Fig. 1.

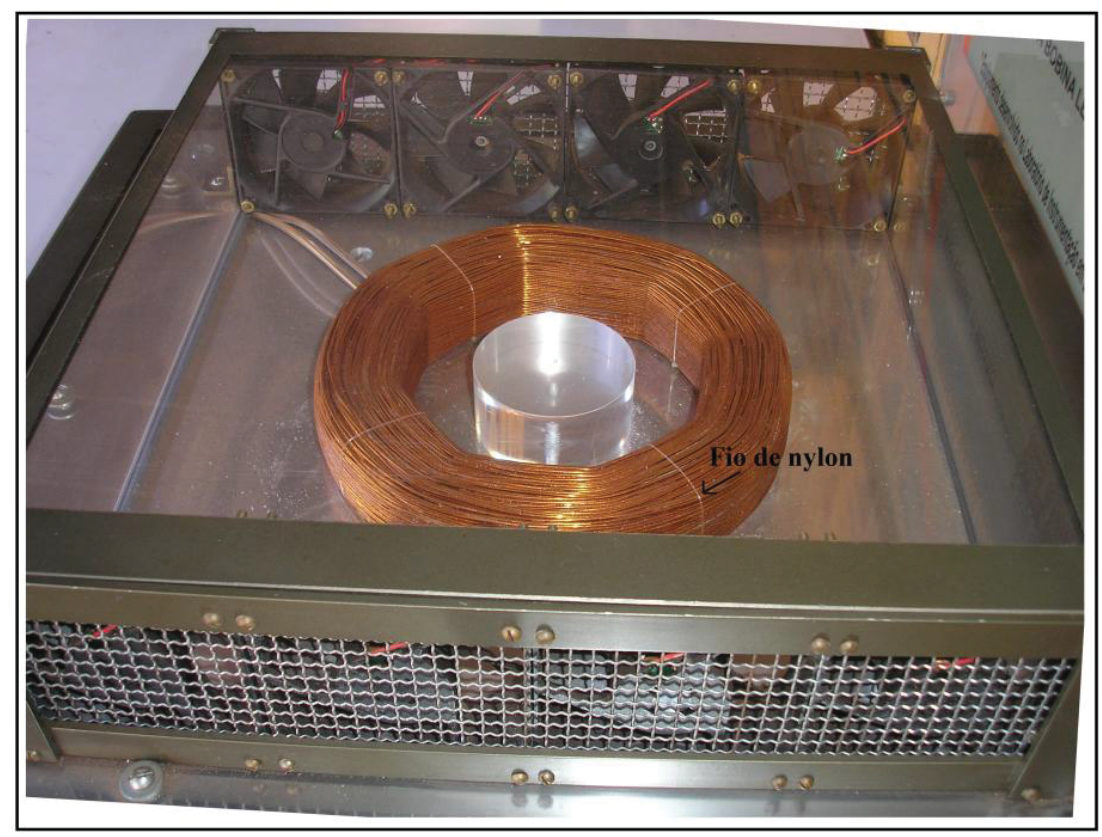

Fig. 1 - Bobina e sistema de refrigeração por ventoinhas.

\footnotetext{
${ }^{15}$ Com referência para um observador posicionado à esquerda da Fig. 1.
} 
Ainda na Fig. 1 se nota, no centro da bobina, um fixo cilindro de acrílico transparente (de $7 \mathrm{~cm}$ de diâmetro e $3 \mathrm{~cm}$ de altura), destinado a impedir que ela tenha inconvenientes movimentos horizontais e colida com as laterais da caixa. Isso é apenas uma prevenção, observado que a bobina deste equipamento, quando bem nivelado, não exibe esses movimentos.

\section{II.2 O circuito de controle automático}

A demonstração deste tipo de levitação obriga uma corrente elétrica 'elevada' na bobina, pois se observa que o surgimento do fenômeno se dá quando o valor em ampères está acima do limite permitido do fio utilizado, acarretando num admirável aquecimento por efeito joule. A experiência mostra que há uma rápida elevação da temperatura da bobina que a impossibilita ficar continuamente ligada à energia elétrica. Inclusive, necessita-se de um considerável tempo de espera relacionado ao seu esfriamento natural em temperatura ambiente para a realização de uma nova levitação, o que justifica um sistema de refrigeração por ventilação como o indicado em subseção anterior. No entanto, para que a bobina não precise ser desligada, exige-se a compensação do aquecimento no mesmo grau do resfriamento por ventilação, situação esta que obrigaria a elaboração de sofisticado dispositivo. Embora o uso das ventoinhas não esteja neste nível de troca de calor, a proposta é simples e acelera a refrigeração da bobina, viabilizando a repetição da sua levitação na prática após um tempo de espera aceitável. Considerando isso e dentro da perspectiva de automatização dos equipamentos em ambientes educativos informais, discute-se agora o circuito eletrônico desenvolvido para facilmente se realizar a demonstração por aperto de um único botão. Os componentes necessários deste circuito de controle automático são: 1 chapa para circuito impresso de $(7 \times 12) \mathrm{cm} ; 1$ resistor de $100 \mathrm{~K} \Omega ; 1$ botão push-button (tipo NA); 1 capacitor de $10 \mathrm{Nf}(16 \mathrm{~V}) ; 1$ resistor de $1 \mathrm{~K} \Omega$; 1 resistor de $330 \mathrm{~K} \Omega$; 1 capacitor de 2,2 uF $(16 \mathrm{~V}) ; 2$ CI 555; 2 resistores de $10 \mathrm{~K} \Omega ; 3$ transistores $\mathrm{BC} 548 ; 1$ chave ligadesliga; 1 resistor de 1,5 M $; 1$ capacitor de $100 \mathrm{uF}$ (16 V); 1 CI 4013; 2 relés de $12 \mathrm{~V} ; 1$ CI 7812; 1 capacitor de 1000 uF (16 V); 2 diodos IN 4007; 1 transformador $^{16} 227 \mathrm{~V}$ para $12 \mathrm{~V}(0,5 \mathrm{~A})$; 1 fio duplo com macho para ligação na tomada.

\footnotetext{
${ }^{16}$ Para uma bobina adaptada aos $127 \mathrm{~V}$, ver comentário da Fig. 2.
} 
A Fig. 2 mostra o esquema elétrico para se desenhá-lo na chapa de circuito impresso com caneta apropriada ${ }^{17}$.

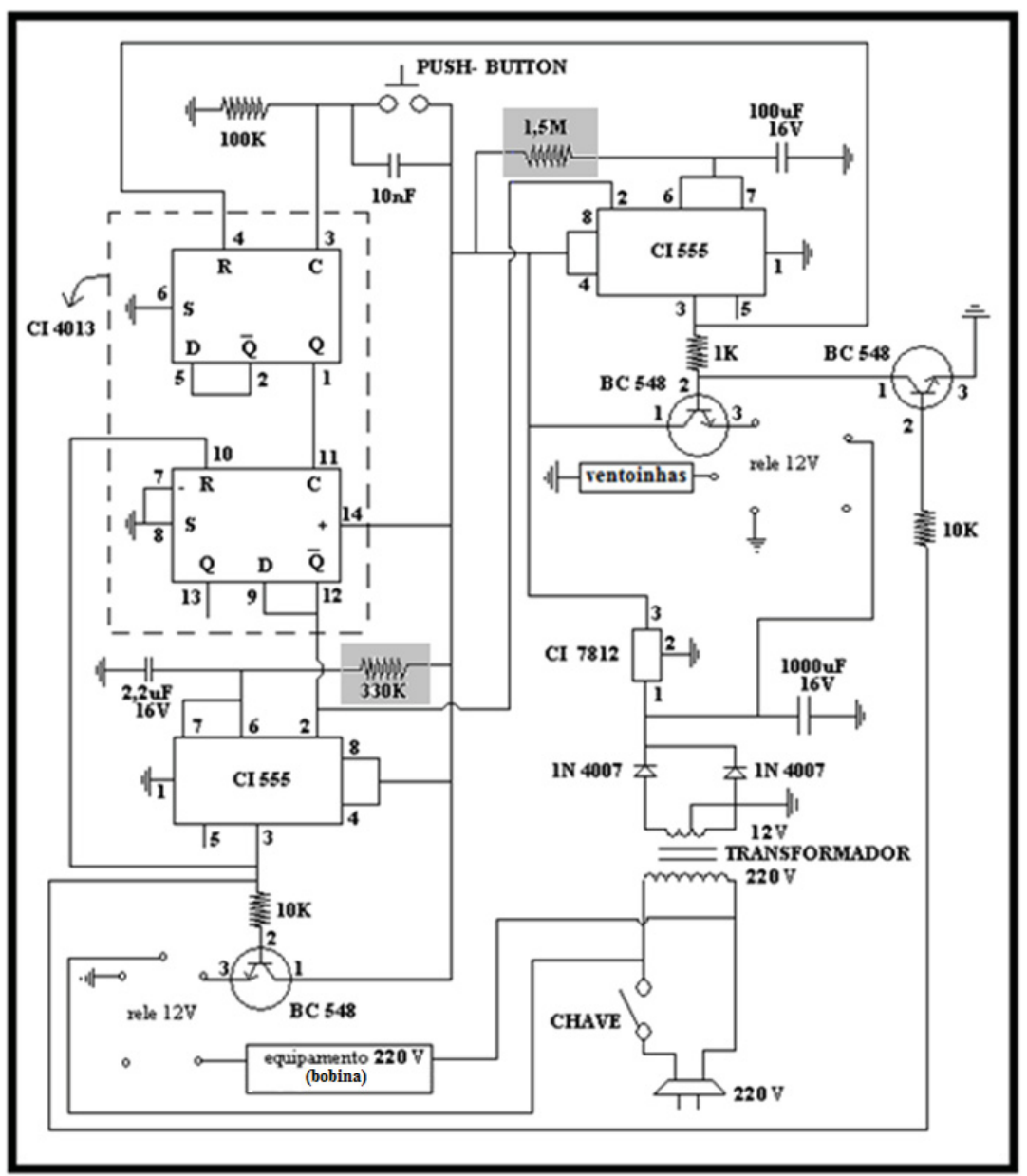

Fig. 2 - Esquema elétrico do circuito de controle automático 18. Para acionar um elemento (bobina) em $127 \mathrm{~V}$, basta trocar o transformador indicado por um de 127 V para $12 \mathrm{~V}$.

\footnotetext{
${ }^{17}$ Pode-se substituir esse método mais tradicional ao usar uma placa de circuito impresso perfurada (pré-furada) de 160×100 mm, onde se encaixam os componentes citados completando todas as ligações com fios tipo cabinho e solda estanho.
} 
Obs.: Se o transformador usado tiver o center-tape (três terminais no primário), opta-se por $220 \mathrm{~V}$ ao excluir o terminal central e aderir os outros dois laterais nas ligações. Já para os $127 \mathrm{~V}$, usa-se o terminal central e um lateral.

Após a realização desse desenho e dos devidos furos para encaixe dos componentes, mergulha-se a chapa em solução de percloreto de ferro para remoção do cobre da sua superfície que não está marcado pela tinta da caneta (trilhas desenhadas). Em seguida, retirar essa tinta lixando a superfície desenhada com lã de aço para posterior encaixe e solda dos componentes nos furos das então restantes trilhas de cobre. Estando aprontado o circuito eletrônico, obedecer às indicações do esquema elétrico para as ligações com a bobina e ventoinhas.

Dessa montagem, o dispositivo eletrônico fica programado a ligar (manualmente por aperto de botão) e, após um tempo estipulado ${ }^{19}$, desligar automaticamente a bobina no mesmo instante em que aciona as ventoinhas também por um determinado tempo ${ }^{20}$. E, enquanto as ventoinhas estiverem funcionando, a programação eletrônica impede que a bobina seja acionada, respeitando o tempo que se apurou ser necessário à refrigeração da mesma com esse método. Logo, nada imprevisto ocorre se um experimentador 'curioso' prosseguir com repentinos acionamentos do botão. Por essa automatização, o equipamento pode ficar continuamente conectado à tomada $(220 \mathrm{~V}$ ou $127 \mathrm{~V})$ sendo a chave liga-desliga opcional.

$\mathrm{O}$ intervalo de tempo que a bobina permanece operando pode ser determinado ao se alterar o resistor destacado na Fig. 3 de $330 \mathrm{~K} \Omega^{21}$, substituindo-o por um resistor variável (trimpot) em cuja escala este valor sugerido é intermediário. O mesmo procedimento pode ser feito para o tempo de espera a um novo acionamento. Neste último caso, o intervalo de tempo é ajustado conforme o valor do resistor

\footnotetext{
${ }^{18}$ Desenvolvimento alcançado por ideias em Saber Eletrônica: $<$ http://www.sabereletronica.com.br/secoes/leitura/1595>.

19

Obedecendo aos valores dos componentes indicados na figura 2, a bobina permanece ligada e levitando por volta de 8 segundos.

${ }^{20}$ Obedecendo aos valores dos componentes indicados na figura 2, as ventoinhas permanecem ligadas por volta de 100 segundos.

${ }^{21}$ Nessa finalidade pode-se também manter o resistor de $330 \mathrm{~K} \Omega$ e trocar o capacitor de $2,2 \mathrm{uF}$ (componente próximo desse resistor em série) por um capacitor variável.
} 
de $1,5 \mathrm{M} \Omega^{22}$ (também em destaque) que está adequado ao tempo em que as ventoinhas permanecem ligadas.

\section{II.3 A montagem final}

Nesta montagem final, uma chapa quadrada de alumínio com lado de $45 \mathrm{~cm}$ e espessura de $13 \mathrm{~mm}$ é usada como base e condutora das correntes induzidas (correntes de Foucault). Para as especificações que se recomendou da energia elétrica à bobina, a experiência revela esta espessura mínima para a maior altura da levitação, pois, no caso de utilizar espessuras menores, ter-se-ão autoindutâncias relativamente menores ainda na chapa ${ }^{23}$. Para efeitos de segurança, a superfície dessa chapa condutora deve ser totalmente envolvida com um isolante, sendo uma boa alternativa a chapa de PVC transparente com cerca de $0,5 \mathrm{~mm}$ de espessura. Assim aprontada e estando fixado o cilindro de acrílico em seu centro (Fig. 1), acomodar a bobina e parafusar a caixa de acrílico (com as ventoinhas laterais) em distâncias simétricas aos cantos dessa base.

Particularmente neste trabalho preferiu-se incrementar três cilindros de material isolante ( $\mathrm{PVC}$ ou equivalente), cada um com $15 \mathrm{~cm}$ de comprimento e $4 \mathrm{~cm}$ de diâmetro, para formarem um tripé e sustentar a base de alumínio. Na Fig. 3 (A), dois deles são visíveis na parte frontal do equipamento, estando o outro posicionado atrás. Usou-se também uma caixa de acrílico pintada (espessura de $5 \mathrm{~mm}) \mathrm{com}$ dimensões de $(30 \times 12 \times 12) \mathrm{cm}$, adaptada sob a base e entre os dois cilindros frontais (visíveis na Fig. 3 (A)), de modo a conter o circuito de controle automático discutido anteriormente e expor o botão push-button à sua frente. As fiações da bobina (terminais) e das ventoinhas atravessam a chapa da base até essa caixa do dispositivo eletrônico, sugerindo-se que os terminais da bobina estejam inseridos em finos tubos de borracha transparente para evitar curtos elétricos entre si e/ou com o alumínio da chapa. Na parte de trás dessa caixa encontram-se a chave liga-desliga e a fiação para a tomada. O equipamento mostrado na Fig. 3 (A) encontra-se numa bancada para livre experimentação na área de exposição pública do MCT, mas, sem o tripé, vale o uso comum de uma cantoneira de ferro para

\footnotetext{
${ }^{22}$ Nessa finalidade pode-se também manter o resistor de $1,5 \mathrm{M} \Omega$ e trocar o capacitor de $100 \mathrm{uF}$ (componente próximo desse resistor em série) por um capacitor variável. 23

Para o comportamento análogo da chapa ao de anéis concêntricos (indutores), vale o comentário de Lang e Axt (2003, p. 84): "A intensidade da corrente elétrica em um indutor sob tensão alternada depende da resistência elétrica e da reatância indutiva (que por sua vez depende da autoindutância e da frequência de alimentação).
} 
deixá-lo imóvel em local definido de uma parede. A foto da Fig. 3 (B) apresenta a levitação da bobina afastada $20 \mathrm{~mm}$ da base.

Concluída esta etapa da montagem, a atenção refere-se à orientação de funcionamento com textos explicativos dos fenômenos. De acordo com a automação feita, é importante destacar uma frase tipo "PRESSIONE O BOTÃO" ao lado deste assim como outra frase com a mensagem "AGUARDAR O TEMPO DE 2 MINUTOS DA REFRIGERAÇÃO DA BOBINA PELAS VENTOINHAS PARA INICIAR UMA NOVA LEVITAÇÃO”. Por esse comando, o aprofundamento dos conceitos físicos em termos qualitativos (e mesmo quantitativos) fica a critério da equipe pedagógica do setor, mas considera-se usual um texto que direciona o que observar com resumida explicação do fenômeno em curtas frases de linguagem inteligível ao público visitante, majoritariamente formado por estudantes do ensino básico e leigos em geral. Na Fig. 3 (A), sobre o equipamento, há um adesivo em um semicírculo com determinados comentários e que exemplifica uma forma de disponibilizar a leitura nesse sentido. Tais comentários estão em anexo, onde se encontram uma explicação do princípio físico da levitação magnética observada para um proveito daqueles interessados na proposta.

\section{Considerações finais}

Há mais de meio século com um papel educativo de divulgar e popularizar a ciência, MCTs concretizaram-se como expositores de uma variedade de aparatos nos quais o público interage movimentando-os, em grande parte, ora por manuseio de manivelas ora por aperto de botões. Por tal natureza em suas essências, a atividade museal em geral ficou apelidada de interatividade push-butoon (DAMICO, 2004, p. 25). Em tempos recentes, uma categorização mais ou menos consagrada da interatividade entre sujeitos e objetos nesses lugares, baseada em Wagensberg (2005), abrange três níveis: a interatividade hands-on - correspondente ao toque e manipulação física ${ }^{24}$; a interatividade minds-on - correspondente ao engajamento intelectual; e a interatividade heart-on - relacionada com a emoção e a cultura. Especificamente para a interação por manipulação, vale então esclarecer que existe o entendimento no qual ela pode ocorrer ou diretamente (hands-on) ou por meio de mecanismos acionados pelo visitante num simples aperto de botão

\footnotetext{
${ }^{24}$ Pela qual se deseja que o visitante "seja o cientista" ao experimentar o método científico por manipulação de objetos, modelos ou montagens que lhe possibilitem entender o funcionamento e o desenrolar de processos e fenômenos.
} 


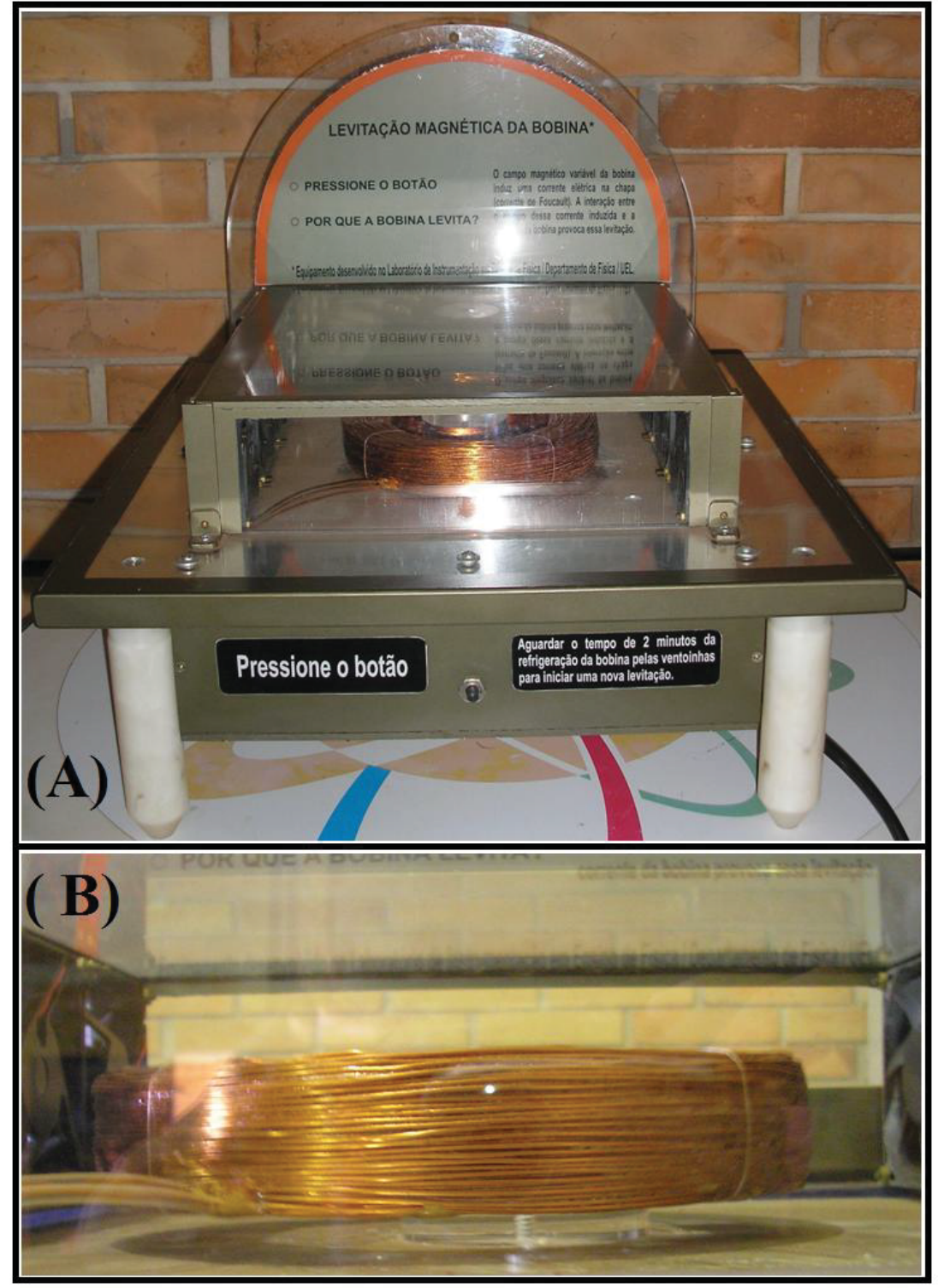

Fig. 3 - (A) Equipamento de levitação magnética de uma bobina da instituição de ensino superior em que se encontram os autores; (B) Bobina em levitação estável. 
(push-button) $^{25}$ (CHELINI; LOPES, 2008, p. 232). Esta ideia de experimentação por manipulação parece estar, segundo Colinvaux (apud CHELINI; LOPES, 2008, p. 231), na origem de vários museus de ciências, tendo-se "a interatividade a palavra ordem" (PAVÃO; LEITÃO, 2007, p. 44). E a Física, conta Pavão (AGÊNCIA CIÊNCIA WEB, 2009), talvez pela facilidade dessa interatividade por manipulação, historicamente tem sido a grande atração nos museus de ciência.

Nesse contexto, o equipamento aqui proposto de levitação magnética adequa-se à educação informal desses ambientes relacionado à primordial interatividade push-button. Devido à automatização empregada, esta exposição é útil por permitir que todos ${ }^{26}$ facilmente realizem a demonstração com segurança. No entanto, a crítica particular nas interações push-button é que o apertar do botão ocorra como "compulsão psicomotora", sem que o visitante ao menos aguarde a conclusão do efeito produzido nem se deixe alargar sua percepção e cognição, haja vista que a resposta é única e não é possível fazer funcionar diferente a fim de se testar uma hipótese (MASSABKI, 2011, p. 62). Este último caso, por outro lado, não é tido como alternativa superior uma vez que Eason e Linn (apud GASPAR, 1993, p. 145) destacam a verificação de diferença não significativa no grau de aprendizagem entre interatividades push-button e hands-on. Para outra comparação ainda maior, Studart (2003, p. 35) descreve as investigações de Blud com cinquenta grupos familiares abrangendo uma exposição completamente interativa, uma do tipo "aperta-botão" e uma estática, concluindo que não houve diferença significativa de aprendizado de conteúdos específicos entre os participantes de cada uma das três exposições, apesar de as primeiras promoverem mais discussões. Considerando isso e coerente com o que se recomendou em seção anterior, cabe ao equipamento de levitação magnética a orientação de Gaspar (2003) na qual um texto explicativo a ele anexado contribui para uma clareza de entendimento, pois, "os visitantes, na sua maioria, leem os textos apresentados pelo menos até que tenham uma ideia do objetivo ou proposta da demonstração" (ibid., p. 148). Aliás, conforme alerta o diretor da $\mathrm{ABCMC}^{27}$, Antônio Carlos Pavão, os centros e museus de ciência "não são espaços para aprender ciência, mas sim para estimular o interesse

\footnotetext{
${ }^{25}$ Tipo de interatividade manipulativa (PADILLA, 2001, p. 123) que resulta num direcionado processo ou fenômeno a ser pensado.

${ }^{26}$ Considerando o grande número de crianças nesses locais.

${ }^{27}$ Associação Brasileira dos Centros e Museus de Ciência.
} 
dos estudantes. À escola cabe o papel de organizar esse conhecimento" (AGÊNCIA CIÊNCIA WEB, 2009).

Por fim, este trabalho forneceu uma alternativa aos MCTs interessados neste tipo de demonstração física, na medida em que seguem o objetivo de continuamente aprimorarem e ampliarem seus acervos de equipamentos interativos. Numa perspectiva de entretenimento, o aparato científico-educacional, além de poder favorecer a curiosidade dos visitantes no tema, é desconhecido do público leigo em geral.

\section{Agradecimentos}

À CAPES/PIBID e ao CNPq pelo apoio financeiro.

\section{Referências}

AGÊNCIA CIÊNCIA WEB (Agência Multimídia de Difusão Científica e Educacional - IEA/USP). Museus de Ciência: o conhecimento de forma divertida. (2009). Conteúdo Jornalístico. Disponível em: $<\mathrm{http}: / /$ agenciacienciaweb.wordpress.com/2009/02/06/museus-de-ciencia-oconhecimento-de-uma-forma-divertida/ $>$. Acesso em: 25 mai. 2013.

BERKELMAN, P.; DZADOVSKY, M. Single Magnet Levitation by Repulsion using a Planar Coil Array. In: IEEE - INTERNATIONAL CONFERENCE ON CONTROL APPLICATIONS, $17^{\text {th }}$, Part of 2008 IEEE Mult-conference Systems and Control, San Antonio, Texas. p. 108-113.

BLEULER, H. A Survey of Magnetic Levitation and Magnetic Types. JSME International Journal, Series III, v. 35, n. 3, p. 335-342, 1992.

BONATO, M. P. O.; SEIBEL, M. I.; MENDES, I. A. Ação mediada em museus de ciências: o caso do Museu da Vida. In: MASSARANI, L; MERZAGORA, M.; RODARI, P. (Orgs.). Diálogos \& Ciência: mediação em museus e centros de Ciência. Rio de Janeiro: Museu da Vida/ Casa de Oswaldo Cruz/ Fiocruz, 2007.

CHELINI, M. E.; LOPES, S. G. B. C. Exposições em museus de ciências: reflexões e critérios para análise. Anais do Museu Paulista, v. 16, n. 2, p. 205-238, juldez, São Paulo, 2008. 
COSTA, G. C. Estudo da levitação magnética e determinação da corrente crítica de blocos supercondutores de alta $\mathbf{T}_{\mathbf{c}}$ pelo método dos elementos finitos. 2005. Tese (Doutorado em Ciências em Engenharia Civil). Disponível em: $<$ http://wwwp.coc.ufrj.br/teses/doutorado/inter/2005/Teses/COSTA_GC_05_t_D_i nt.pdf $>$. Acesso em: 23 abr. 2013.

CONSTANTIN, A. C. C. Museus interativos de ciências: espaços complementares de educação? Interciencia, v. 26, n. 5, p. 195-200, mayo, 2001.

DAMICO, J. S. Uma nova relação estrutural para a sustentabilidade do Museu da Vida. 2004. Dissertação (Mestrado em Gestão de Ciência, Tecnologia e Saúde) Rio de Janeiro.

LEVITACIÓN DE UMA BOBINA SOBRE UNA PLACA DE ALUMINIO (coil levitation over an aluminium plate). Disponível em:

$<\mathrm{http}: / /$ www.youtube.com/watch?v=PXmrJvEi7Fs\&NR=1\&feature=endscreen $>$. Acesso em: 27 mai. 2013.

ELECTROSTATIC LEVITATION. Disponível em:

$<$ https://www.youtube.com/watch?v=DRBAPd7NOIE $>$. Acesso em: 07 mai 2013.

GASPAR, A. Museus e Centros de Ciências: conceituação e proposta de um referencial teórico. 1993. Tese (Doutorado na área de Didática). Faculdade de Educação, Universidade de São Paulo, São Paulo.

GLOBO MAGNÉTICO DE LEVITAÇÃO. Disponível em: http://www.youtube.com/watch?v=QBPvHoM8lnc. Último acesso: 25/04/2013.

ISZLAJI, C. A criança nos Museus de Ciências: análise da exposição mundo da criança do museu de ciência e tecnologia da PUCRS. 2012. Dissertação (Mestrado em Ensino de Ciências) - Instituto de Física, Instituto de Química, Instituto de Biociências e Faculdade de Educação, Universidade de São Paulo, São Paulo.

JAYAWANT, B. V. Electromagnetic suspension and levitation. Rep. Prog. Phys., v. 44, p. 411-472, 1981. Disponível em: <http://iopscience.iop.org/00344885/44/4/002 >. Acesso em: 23 abr. 2013. 
JEON, J. U.; HIGUCHI, T. Induction Motors with Electrostatic Suspension. Journal of Electrostatics, v. 45, p. 157-173, 1998.

LANG, F. S.; AXT, R. Explicação qualitativa do "anel de Thomson". Como ocorre a "levitação magnética"? Revista Brasileira de Ensino de Física, v. 25, n. 1, p. 81-85, 2003.

LEE, H.; KIM, K.; LEE, J. Review of Maglev Train Technologies. IEEE Transactions on Magnetics, v. 42, n. 7, p. 1917-1925, july, 2006.

LEVITAÇÃO DE DISCO - LASUP/UFRJ. Disponível em:

$<$ http://www.youtube.com/watch? v=BWYCe1PBoW8 $>$. Acesso em: 18 nov. 2013.

LEVITAÇÃO MAGNÉTICA. Disponível em:

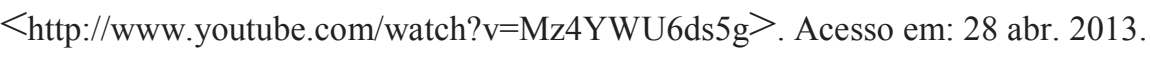

LEVITAÇÃO MAGNÉTICA - DISCO RÍGIDO. Disponível em:

$<$ http://www.youtube.com/watch?v=rkxUL__lqyI >. Acesso em: 28 abr. 2013.

LEVITATION WITH THE LEVITRON. Disponível em:

$<$ http://www.youtube.com/watch?v=GMVtlNbMwHw>. Acesso em: 26 abr. 2013.

LEVITRON CASEIRO. Disponível em:

$<$ http://www.youtube.com/watch?v=pNJ2EmR6GNo $>$. Acesso em: 25 abr. 2013.

MASSABKI, P. H. B. Centros e Museus de Ciência e Tecnologia. 2011. Dissertação (Mestre em Arquitetura) - Faculdade de Arquitetura e Urbanismo, Universidade de São Paulo, São Paulo.

PADILLA, J. Conceptos de museos y centros interactivos. P. 113-141. In: CRESTANA, S. et al. (Org.). Curso para treinamento em Centros e Museus de Ciencia: Educação para a ciência. Editora Livraria da Física: São Paulo, 2001.

PAVÃO, A. C.; LEITÃO, A. Hands-on? Minds-on? Hearts-on? Social-on? Explainers-on! In: MASSARANI, L; MERZAGORA, M.; RODARI, P. (Orgs.). Diálogos \& Ciência: mediação em museus e centros de Ciência. Rio de Janeiro: Museu da Vida/ Casa de Oswaldo Cruz/ Fiocruz, 2007. 
ROCHA, F. S.; FRAQUELLI, H. A. Roteiro para a experiência de levitação de um ímã repelido por um supercondutor no Ensino de Física. Revista Brasileira de Ensino de Física, v. 26, n. 1, p. 11-18, 2004.

SABER ELETRÔNICA: o seu portal para o universo da eletrônica - on-line. Disponível em: <http://www.sabereletronica.com.br/secoes/leitura/1595>. Acesso em: 28 abr. 2013.

SEARS, F. W.; ZEMANSKY, M. W. Física III: eletromagnetismo. 10. ed. Addison Wesley: São Paulo, 2004.

SILVA, O. H. M.; LABURÚ, C. E. Motor elétrico de Faraday: uma montagem para museus e laboratórios didáticos. Caderno Brasileiro de Ensino de Física, v. 26, n. 3, p. 478-491, 2009.

SILVA, O. H. M.; ZAPAROLLI, F. V. D.; ARRUDA, S. M. Demonstrações em óptica geométrica: uma proposta de montagem para ambientes de educação não formal. Caderno Brasileiro de Ensino de Física, v. 29, n. 3, p. 1199-1199, dez. 2012.

SILVA, O. H. M.; ARRUDA, S. M.; LABURÚ, C. E.; BUENO, E. A. S. Pêndulo de Wilberforce: uma proposta de montagem para ambientes educativos informais e laboratórios didáticos. Caderno Brasileiro de Ensino de Física, v. 30, n. 2, p. 409-426, ago. 2013a.

SILVA, O. H. M; ALMEIDA, A. R.; ZAPAROLLI, F. V. D.; ARRUDA, S. M. Convergência e divergência de raios de luz por lentes e espelhos: um equipamento para ambientes planejados de educação informal. Caderno Brasileiro de Ensino de Física, v. 30, n. 2, 2013 b.

STUDART, D. C. Famílias, exposições interativas, e ambientes motivadores em museus: o que dizem as pesquisas? In: STUDART, D. C. (Org.). Avaliação e estudos de públicos no Museu da Vida. Rio de Janeiro: Museu da Vida, 2003. p. $33-42$.

VALLE, R. L. S.; NEVES, F. F.; DE ANDRADE, R.; STEPHAN, R. M. Electromagnetic Levitation of a Disc. IEEE Transactions on Education, v. 55, p. 248254,2012 
VALENÇA, V. L. C. A criação do Museu das Crianças de Santa Catarina: uma experiência em andamento. Perspectiva, v. 24, n. 1, p. 319-338, jan/jun 2006.

WAGENSBERG, J. Museus devem divulgar ciência com emoção. Entrevista concedida a Germana Barata. Ciência e Cultura, São Paulo, v. 55, n. 2, p. 16-17, abr./jun. 2003.

WAGENSBERG, J. O Museu "Total”, uma ferramenta para a mudança social. In: CONGRESSO MUNDIAL DE CENTROS DE CIÊNCIA, 4, 2005, Rio de Janeiro.

\begin{abstract}
Anexo
Explicação qualitativa do fenômeno da levitação magnética da bobina

Classifica-se esta levitação como sendo um tipo de levitação eletrodinâmica. No caso, a fixa chapa de alumínio especificada encontra-se posicionada logo abaixo da bobina móvel de corrente elétrica alternada $(60 \mathrm{~Hz})$ e campo magnético igualmente variável no tempo que, por sua vez, induz correntes elétricas circundantes ao longo do volume do material dessa chapa. Estas correntes induzidas assemelham aos remoinhos das águas em um rio e são comumente chamadas de correntes de remoinho, correntes parasitas ou correntes de Foucault (SEARS; ZEMANSKY, 2004, p. 287). A Fig. 4 idealiza uma configuração dessas correntes que fluem através do metal da chapa com campos magnéticos próprios que interagem com a bobina móvel portadora de corrente, havendo indutância mútua. Mais especificamente, e por uma questão de referencial, os campos magnéticos das correntes de Foucault fazem com que a corrente elétrica da bobina sofra a ação de forças magnéticas conforme a expressão: $F=\mathrm{I} L \times \quad B$. À direita da Fig. 4 tem-se uma região da bobina ampliada para melhor esclarecimento da aplicação dessa expressão pela regra da mão esquerda (ibid.). Ela ilustra a corrente elétrica de uma única espira (direção perpendicular ao plano da página e sentido entrando na mesma) com a força magnética atuando para cima. Conclusão esta que se obtém para quaisquer regiões das espiras da bobina quando se considera que ela tenha corrente elétrica crescente, no sentido indicado na Fig. e por avaliação do comportamento da corrente de Foucault na chapa (Fig. 4), mediante a força eletromotriz induzida em oposição à taxa de variação do fluxo magnético (lei de Lenz).

Todavia, o fenômeno dessa levitação não se limita ao efeito repulsivo descrito acima, pois a corrente elétrica na bobina é alternada e a interação magnética entre duas circulares correntes elétricas paralelas (no caso, a da bobina e a da
\end{abstract}




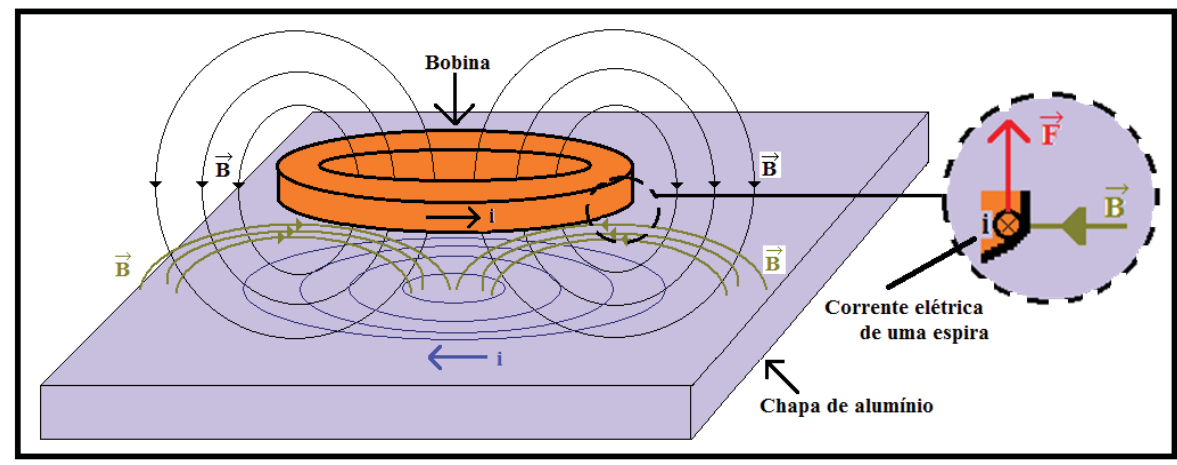

Fig. 4 - Idealização da configuração de correntes de Foucault induzidas na chapa e interação magnética.

chapa) pode ser atrativa (quando as correntes estão no mesmo sentido) ou repulsiva (quando as correntes estão em sentidos opostos). Ocorre que a intensidade de ambas as interações não é a mesma, sendo o efeito preponderante repulsivo. Isto porque a corrente elétrica alternada na bobina é matematicamente descrita por uma curva senóide $^{28}$. De acordo com a lei de Faraday-Lenz, a força eletromotriz induzida na chapa é dada pela função cosseno multiplicada por menos um, atrasando-se $1 / 4$ de ciclo $\left(90^{\circ}\right)$ em relação à corrente da bobina. Por sua vez, a corrente elétrica na chapa não terá sempre o mesmo sinal dessa força eletromotriz por motivo de autoindutância, que funciona como se a corrente elétrica tivesse "inércia" e determina que esta corrente se atrase em relação à força eletromotriz induzida. O papel da autoindutância na chapa faz com que o atraso de sua corrente em relação à da bobina seja ainda maior do que $1 / 4$ de ciclo (pois, à defasagem de $1 / 4$ de ciclo entre a corrente da bobina e a força eletromotriz induzida, acrescenta-se o atraso da corrente induzida em relação à correspondente força eletromotriz). Se o material da chapa não tivesse resistência elétrica alguma, suas correntes induzidas não teriam sentidos opostos à da bobina e, consequentemente, haveria sempre repulsão magnética entre elas. No entanto, a chapa possui resistência elétrica não nula cujo relativo atraso de sua corrente elétrica pode ser graficamente representado para um ciclo completo conforme a Fig. 5. Podem-se notar ao longo desse ciclo as duas regiões com atração e duas com repulsão pelas quais se evidencia o efeito médio repulsivo preponderante.

\footnotetext{
${ }^{28}$ A explicação que se segue deve-se a Lang e Axt (2003, p. 83 e 84).
} 


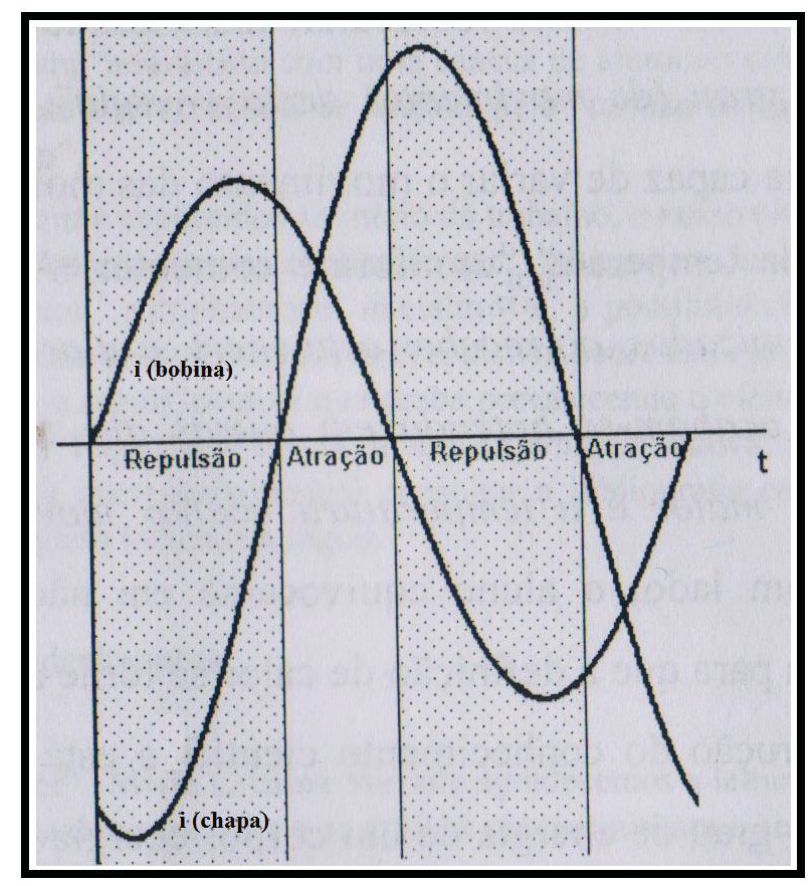

Fig. 5 - Defasagem das correntes por mais do que $1 / 4$ de ciclo e menos do que 1/2 ciclo (LANG; AXT, 2003, p. 84).

Esta discussão acerca do princípio físico da levitação em foco serve para auxiliar os interessados em atrelar um texto explicativo no equipamento adaptado ao público visitante. Admite-se que demasiados detalhes possam ser excluídos a critério da equipe pedagógica do local. Porém, antes de uma leitura nesse sentido e posto o título "LEVITAÇÃO MAGNÉTICA DA BOBINA", pelo menos uma pergunta para reflexão ${ }^{29}$ seja importante.

\footnotetext{
${ }^{29}$ Como: "Por que a bobina levita?".
} 